\title{
Seepage into Drifts in Unsaturated Fractured Rock at Yucca Mountain
}

\author{
Jens Birkholzer, Guomin Li, Chin-Fu Tsang, Yvonne Tsang \\ LBNL, ESD
}

An important issue for the long-term performance of underground nuclear waste repositories is the rate of seepage into the waste emplacement drifts. A prediction of the future seepage rate is particularly complicated for the potential repository site at Yucca Mountain, Nevada, as it is located in thick, partially saturated, fractured tuff formations. The long-term situation in the drifts several thousand years after waste emplacement will be characterized by a relative humidity level close to or equal to $100 \%$, as the drifts will be sealed and unventilated, and the waste packages will have cooled. The underground tunnels will then act as capillary barriers for the unsaturated flow, ideally diverting water around them, if the capillary forces are stronger than gravity and viscous forces. Seepage into the drifts will only be possible if the hydraulic pressure in the rock close to the drift walls increases to positive values; i.e., the flow field becomes locally saturated.

In the present work, we have developed and applied a methodology to study the potential rate of seepage into underground cavities embedded in a variably saturated, heterogeneous fractured rock formation. The fractured rock mass is represented as a stochastic continuum where the fracture permeabilities vary by several orders of magnitude. Three different realizations of random fracture permeability fields are generated, with the random permeability structure based on extensive fracture mapping, borehole video analysis, and in-situ air permeability testing. A 3-D numerical model is used to simulate the heterogeneous steady-state flow field around the drift, with the drift geometry explicitly represented within the numerical discretization grid. A variety of flow scenarios are considered assuming present-day and future climate conditions at Yucca Mountain. The numerical study is complemented by theoretical evaluations of the drift seepage problem, using stochastic perturbation theory to develop a better understanding of the key processes involved.

We found that, for the conditions at Yucca Mountain, the heterogeneity in the flow domain is a key factor controlling the rate of seepage into drifts, because the "channelized" flow in high-permeability features promotes local ponding conditions close to the drift walls. Figure 1 shows a typical flow field in the vicinity of the drift, presenting saturation contours in three horizontal slices of the 3-D model domain for a future climate scenario of $200 \mathrm{~mm} / \mathrm{yr}$ percolation flux. In the horizontal plane just above the drift (middle horizontal slide), liquid accumulates at the drift crown as the vertical gravity-driven flow is diverted around it, while in the horizontal plane below the drift a low-saturation shadow develops. In addition to this flow perturbation effect, the saturation contours reflect the heterogeneity of the model area, showing several locations where "channelized" flow accumulates creating high saturation values dependent on local permeability contrasts. In fact, at some of these locations, the saturation reaches unity, representing a local ponding condition. Obviously, the probability that local ponding 
occurs is highest near the stagnation point at the drift crown. Eventually, seepage into the drift occurs when a local ponding condition is encountered in a grid element adjacent to the drift wall.

Various flow scenarios have been simulated with percolation fluxes ranging from $5 \mathrm{~mm} / \mathrm{yr}$ to $1000 \mathrm{~mm} / \mathrm{yr}$. Figure 2 summarizes the results of these simulation runs for the three realizations considered; it gives the total seepage flux into the drift as a function of the inflow at the top boundary of the model. The seepage flux is expressed as a percentage of the percolation flux over an area corresponding to the vertical shadow of the drift. As shown in Figure 2, seepage into drifts at Yucca Mountain is likely to start when steady-state percolation fluxes are tens of millimeters per year, the rate of seepage being strongly dependent on the assumed percolation scenario. Thus for future climate conditions with higher infiltration than the present state, drifts at Yucca Mountain will be vulnerable for water to enter. In comparison to results obtained for a homogeneous flow field; the seepage threshold fluxes are about an order of magnitude smaller, indicating the important effect of local saturation variations (local ponding). Indeed, as Figure 3 shows, the probability that local ponding conditions occur in the simulated flow fields is closely related to the potential rate of seepage into the drifts. The ponding probability given in this figure is calculated as the number of simulation grid blocks with positive or zero pressure values divided by the total number of grid blocks in the model area.

As the seepage probability is strongly dependent on details of the local heterogeneity around the drift walls, the variation between the three different realizations is significant. Particularly for small percolation fluxes where seepage locations along the drifts are sparsely distributed, the model domain size might not be sufficient to guarantee a large enough statistical sample. Ultimately, an analytical stochastic relationship would be very useful to estimate the potential rate of seepage as a function of different key parameters. As a first step in this direction, we evaluated the seepage probability from stochastic perturbation analysis by calculating the likelihood of local ponding in a heterogeneous flow field, without the presence of the drift. For the conditions found at Yucca Mountain, the results compared favorably with the numerical simulations which include the effect of the drift acting as an obstacle for the unsaturated flow (Figure 4). Sensitivities derived from these theoretical considerations indicate that, in addition to the assumed percolation scenario, the potential rate of seepage is strongly affected by the degree of heterogeneity and the mean fracture permeability.

The studies presented here were intended to be exploratory, with the specific conditions encountered at Yucca Mountain used as an example. We believe that the conceptual framework developed for the study of seepage into underground drifts at Yucca Mountain can be useful for a variety of other hydrogeologic and engineering applications. Our modeling effort was not intended as a complete stochastic analysis which would involve a Monte-Carlo type study of various random structures. In future work, we will examine a broader variety of heterogeneity fields and a larger number of realizations. Laboratory experiments and field tests on drift seepage in unsaturated heterogeneous fractured formations should be performed and used to confirm the theoretically and numerically derived conclusions from this paper. 


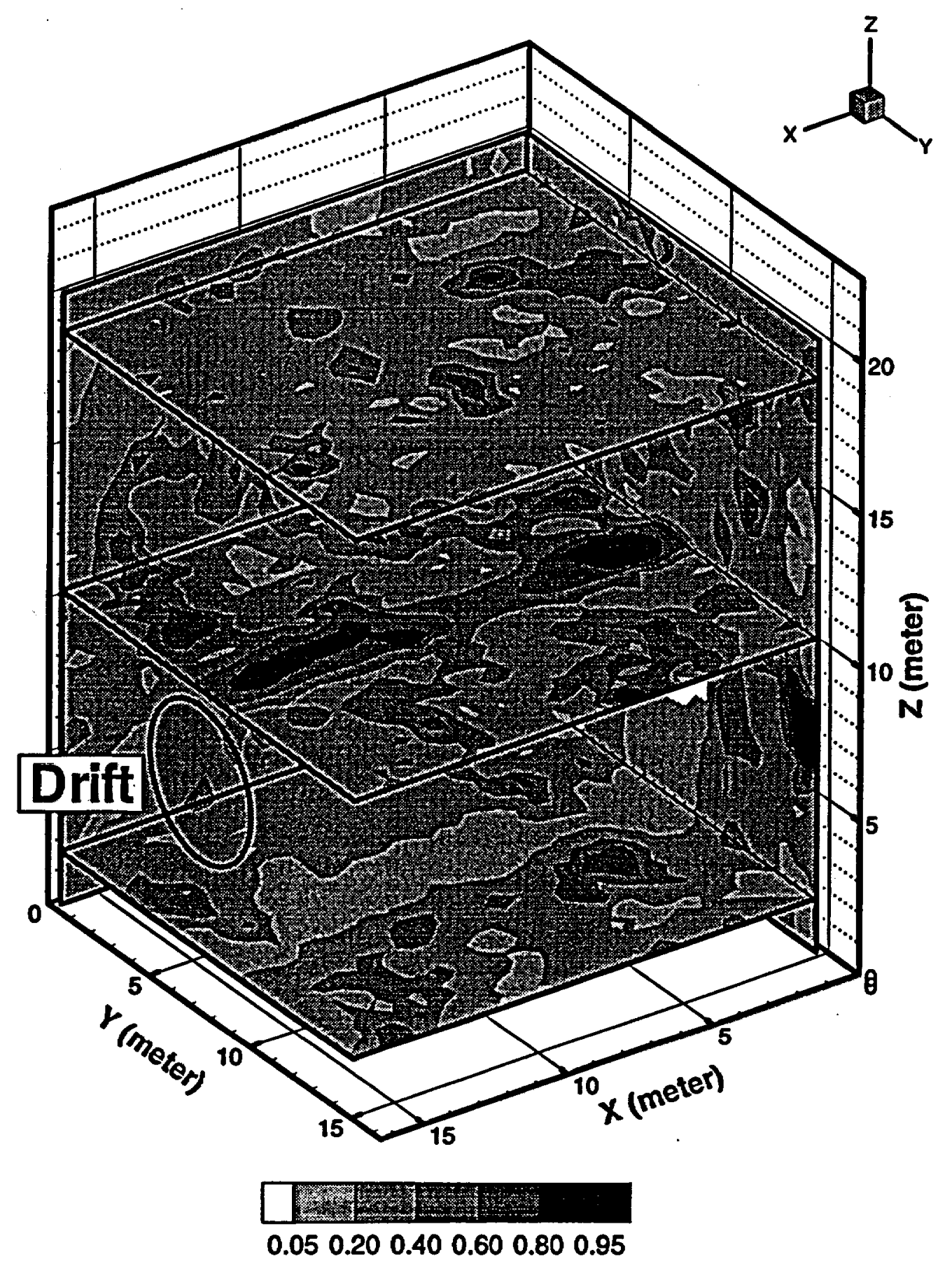

Figure 1: Saturation contours for a percolation flux of $200 \mathrm{~mm} / \mathrm{yr}$ 


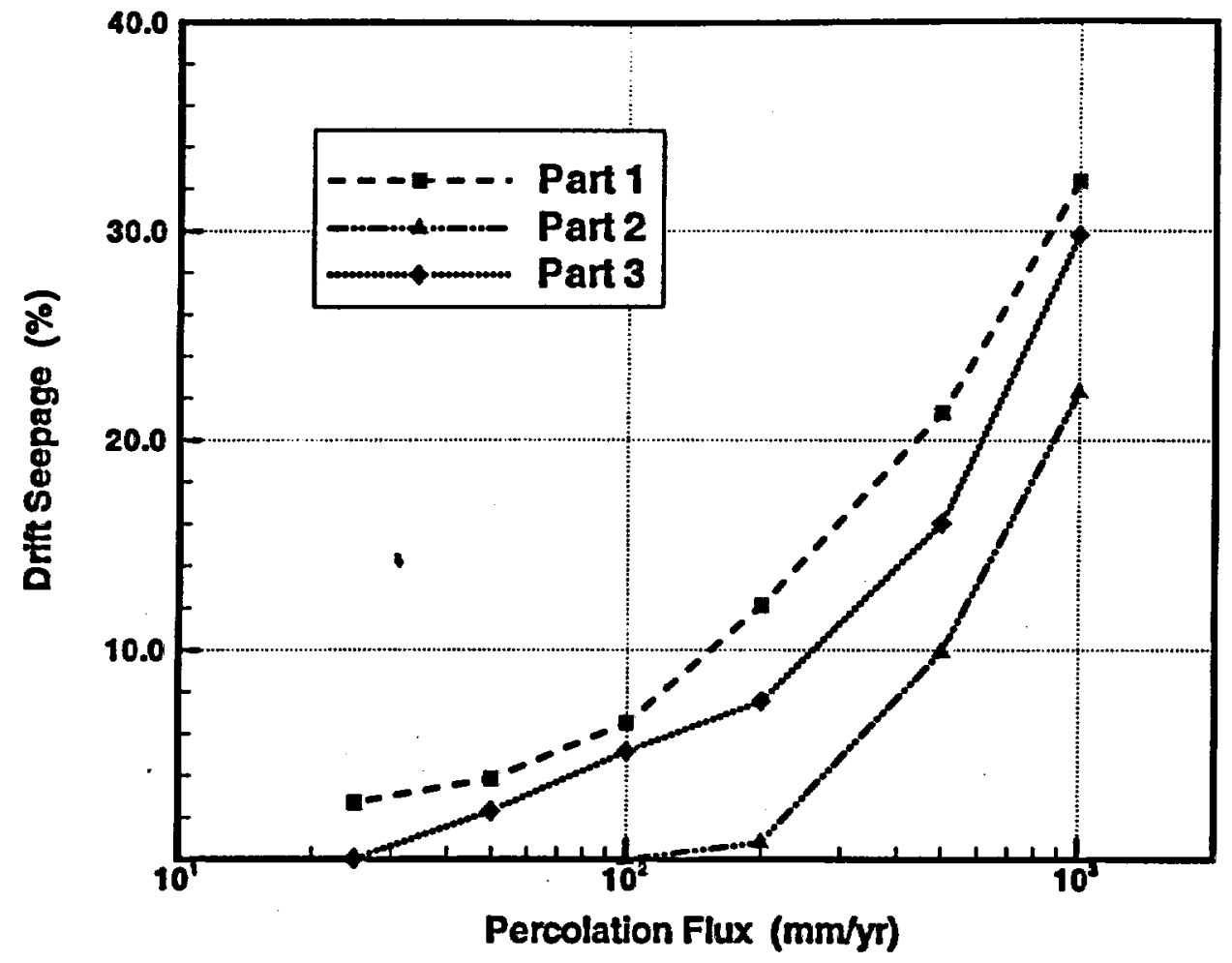

Figure 2: Relative seepage rate for three realizations of random fields (Part 1, Part 2 and Part 3). Only those simulation runs are presented where seepage into the drift oocurs.

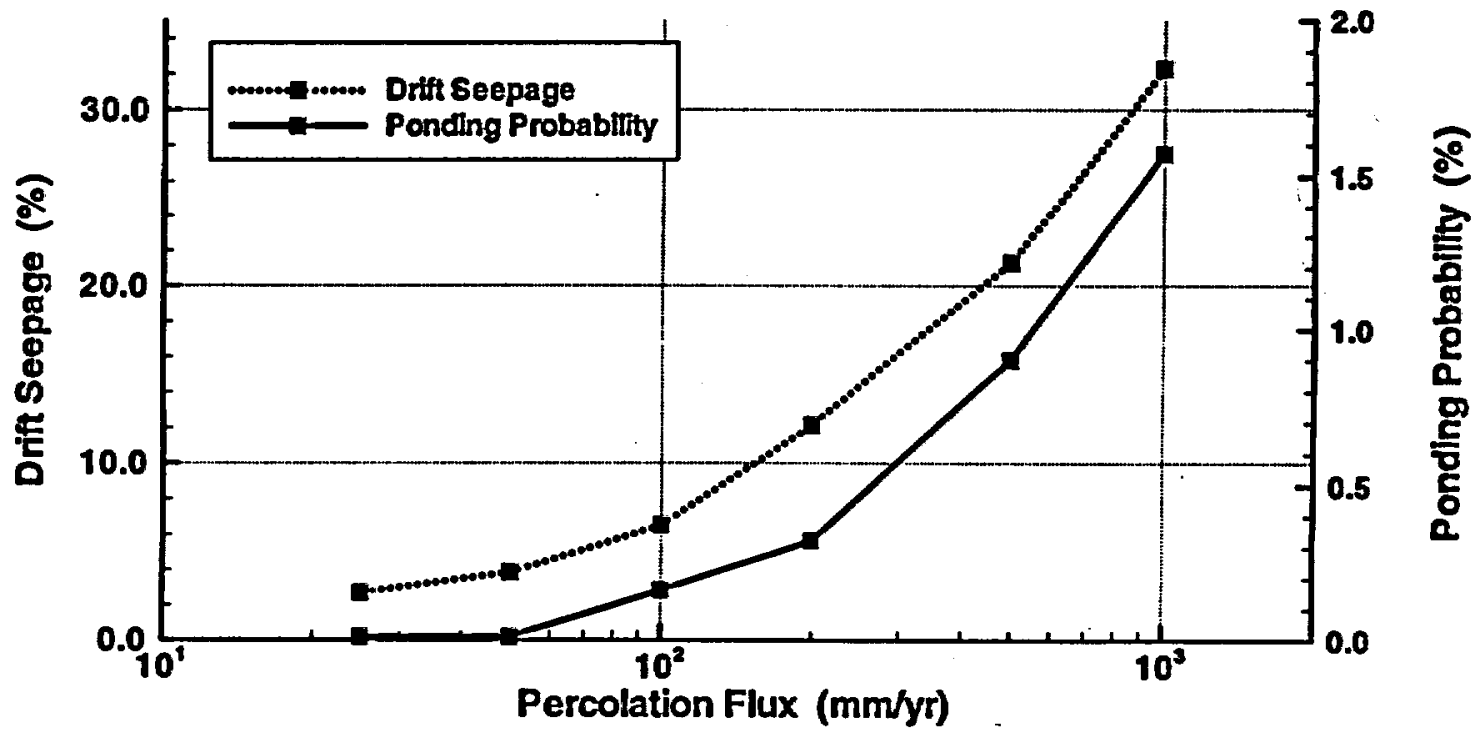

Figure 3: Relative seepage rate and ponding probability for one realization (Part 1). Only those simulation runs are presented where seepage into the drift occurs. 


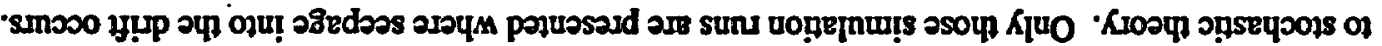

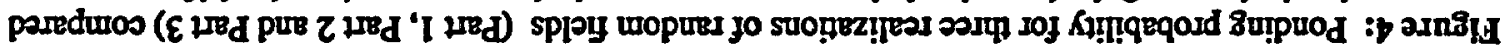

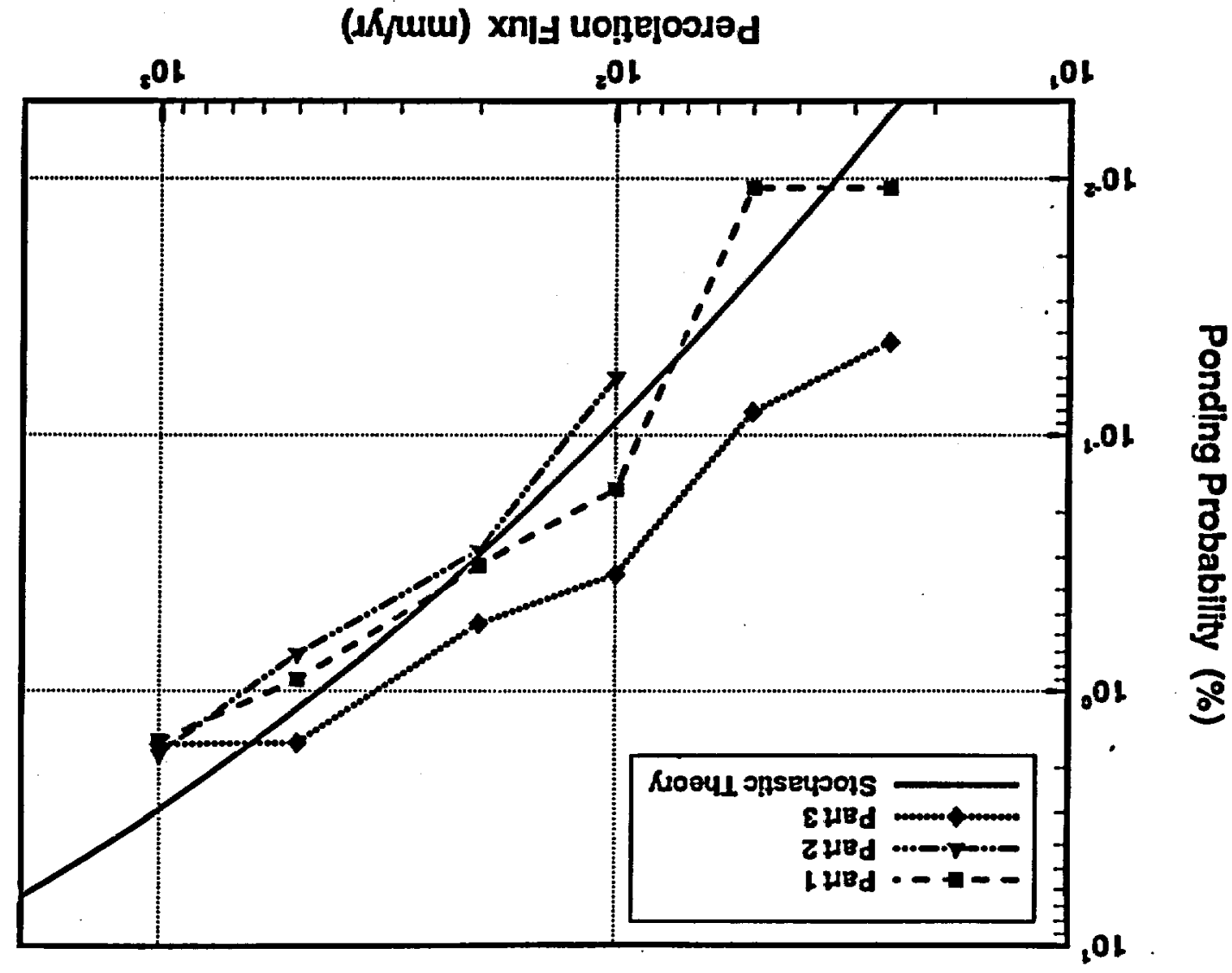

